\title{
Movement behaviors, cardiorespiratory fitness, and cardiovascular disease risk factors in children from the gulf cooperation council countries: A narrative review
}

Mohummed Hamad Alkhraiji ${ }^{1,2}$, Alan Robert Barker ${ }^{1}$, Craig Anthony Williams ${ }^{1}$

${ }^{1}$ Children's Health and Exercise Research Centre, Sport and Health Sciences, College of Life and Environmental Sciences, University of Exeter, Exeter, London, UK, ${ }^{2}$ Department of Exercise

Physiology, College of Sport Sciences and Physical Activity, King Saud University, Riyadh, Saudi Arabia

Address for correspondence: Prof. Craig Anthony Williams, Children's Health and Exercise Research Centre, Sport and Health Sciences, College of Life and Environmental Sciences, St. Luke's Campus, University of Exeter, Heavitree Road, Exeter, Devon, EX1 2LU, United Kingdom.

E-mail: c.a.williams@exeter.ac.uk

\begin{abstract}
Movement behaviors inclusive of physical activity (PA), sedentary behavior (SB), and sleep time (ST), and cardiorespiratory fitness (CRF) are associated with cardiovascular disease (CVD) risk factors in children. The aim of this narrative review is to synthesize data on movement behaviors (PA, SB, and ST) and CRF in relation to CVD risk factors in children from the Gulf Cooperation Council (GCC). Three online databases were searched up until August 2019. Movement behaviour studies were included if cut-offs were $\geq 60 \mathrm{~min} /$ day for PA, $\leq 2$ or $\leq 3 \mathrm{~h} /$ day for SB (screen time), and $\geq 8$ or $\geq 9 \mathrm{~h} /$ day for ST. Laboratory- and field-based CRF measures were included. Thirty-five studies were included in the review. Participants were aged 8-19 years old. Seven studies were on males and one study on femaleonly participants. PA was reported in 13 studies, with $28 \%$ considered physically active. SB was reported in 13 studies and $56 \%$ met the guidelines. Only one study measured ST, with $23 \%$ meeting the recommendation. Eight studies measured $\mathrm{CRF}$, and in six of these studies, the mean maximal oxygen uptake $\left(\mathrm{VO}_{2 \max }\right)$ was 42 and $36 \mathrm{~mL} / \mathrm{kg} / \mathrm{min}$ for males and females, respectively. Two studies used the one-mile walk/run test on male participants, with a mean performance time of $10 \mathrm{~min}$. One study investigated multiple CVD risk factors in relation to CRF, and four studies with body mass index (BMI) only. One study on PA and SB was examined in relation to BMI. Overall, weak correlations were found between movement behaviors and CRF in relation to CVD risk factors. The prevalence of meeting PA and ST guidelines among children from GCC is low. On average, CRF is slightly above the proposed healthy cut off points for both genders. Future prospective research is needed on children from the GCC to comprehensively examine the relationship between movement behaviors, CRF and CVD risk.
\end{abstract}

Keywords: Epidemiology, physical activity, physical fitness, school children, sedentary time, sleep

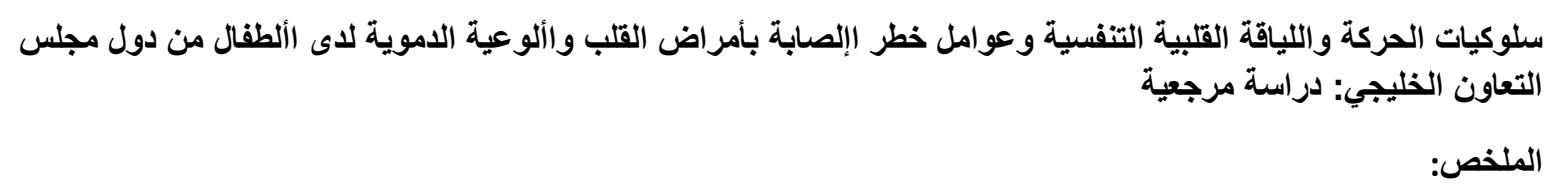




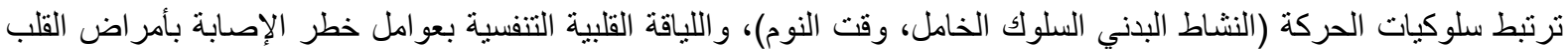

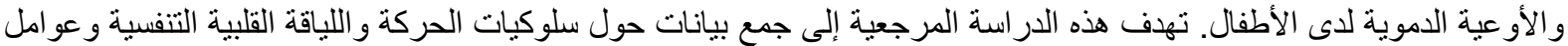

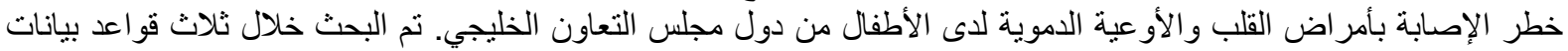

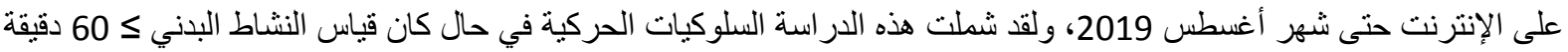

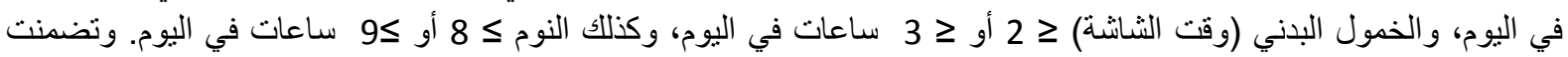

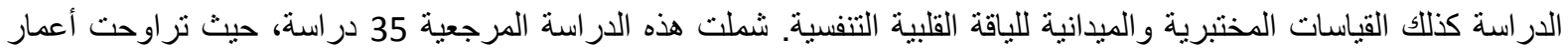

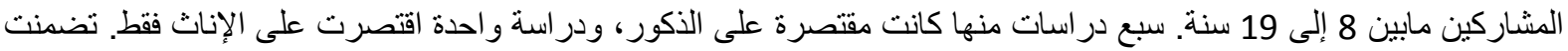
هذه الدراسة المرجعية 13 دراسة عن النشاط البدني و التي أظهرت بأن 28 \%

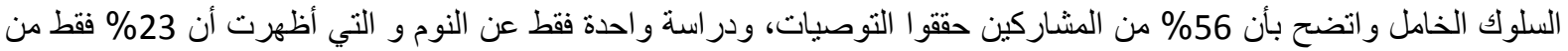

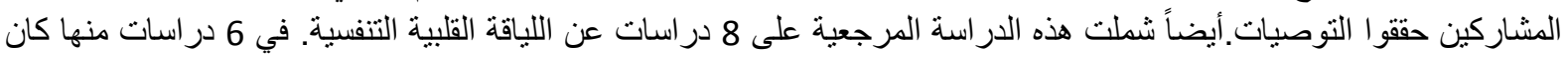

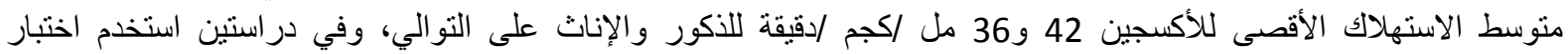

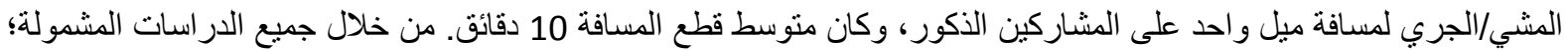

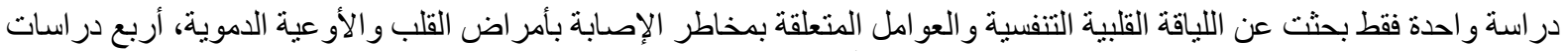

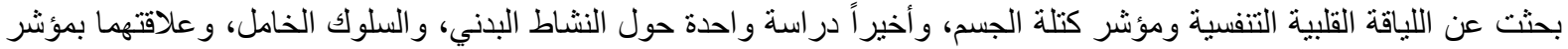

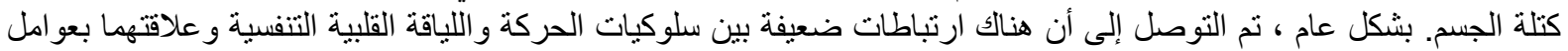

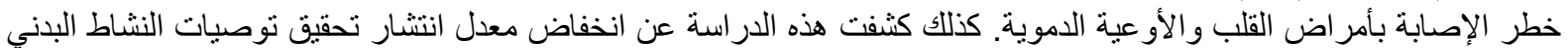

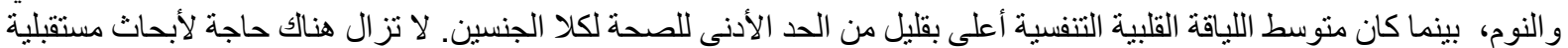

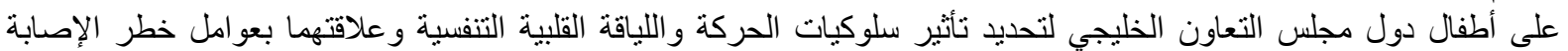
بأمر اض القلب و الأو عية الدموية النعارن

\section{NTRODUCTION}

The Gulf Cooperation Council (GCC) consists of six countries, namely Saudi Arabia, United Arab Emirates, Kuwait, Bahrain, Oman, and Qatar.[1] The prevalence of mortality due to cardiovascular diseases (CVD) is 35\% in the GCC region.[2] A systematic review highlights the high prevalence of several CVD risk factors (obesity, type 2 diabetes, hypertension, and dyslipidemia) in adults from the GCC, which is a major public health issue.[3] This concern extends to children from the GCC,[4] as they also present with CVD risk factors (high low?density lipoprotein cholesterol, low high?density lipoprotein cholesterol, hypertriglyceridemia, pre?hypertension, and central obesity).[508] Several studies have documented that the origin of CVD begins in childhood, and are related to subclinical changes in CVD risk. $[9,10]$ This underscores the importance of health screening and prevention programs for children from the GCC to mitigate current and future risk of CVD. Movement behaviors, such as physical activity (PA), sedentary behaviors (SB), and sleep time (ST), are daily behaviors found to be independently related to health outcomes in children.[11国15] It is recommended by the World Health Organization (WHO) that children aged 5-17 years should engage in $\geq 60 \mathrm{~min}$ of moderate to vigorous PA (MVPA) daily for promoting health and wellbeing.[16] Studies have also found that recreational screen time $>2 \mathrm{~h}$ /day is positively associated with obesity.[17] In addition, in systematic reviews, total time spent in SB was found to be inversely associated with high?density lipoprotein and positively associated with blood pressure.[14,18] For ST, the National Sleep Foundation recommends ST between 9 to $11 \mathrm{~h} /$ day for 6-13 year olds and 8 to $10 \mathrm{~h} /$ day for $14-17$ year olds.[19] A meta?analysis has reported negative associations between ST duration and risk of obesity in children.[20] In addition to movement behaviors, cardiorespiratory fitness (CRF) in children is related to CVD outcomes, independent of PA and SB.[21,22] Consequently, The European Youth Heart Study has recommended to the Pan?European health monitoring system to include CRF tests as a health screening tool for children.[23] Currently, the suggested minimum average fitness level for male and female 8-17 years old is 42 and $35 \mathrm{~mL} / \mathrm{kg} / \mathrm{min}$, respectively, to indicate elevated CVD risk.[24] Current data on the relationships between movement behaviors and CRF on CVD risk factors are mostly derived from America (North), Australia, and Europe countries, which may not be representative of children from the GCC. Therefore, in children and adolescents from the GCC, this narrative review aims to: (1) 
identify the prevalence of each movement behavior(PA, SB, and ST) and it association with CVD risk factors, and (2) examine CRF level and it relation to CVD risk factors.

\section{METHODS}

This narrative review follows the steps in writing a narrative biomedical review that is recommended by Gasparyan et al.,[25] and are outlined below.

\section{Search}

The review search dates were from September 2018 to August 2019 and were conducted using Google Scholar, PubMed, and the WHO database. The Google Scholar research engine was used initially as it provides research sources from several databases.[26] The PubMed database was used to extend the search to locate articles not found in Google Scholar. Search terms used were related to exposures and outcomes which included: physical activity, physical inactivity, sedentary behavior, sedentary time, screen time, sleep, short sleep duration, cardiorespiratory fitness, maximal aerobic fitness, maximal oxygen uptake, children, adolescents, blood pressure, hypertension, lipids, dyslipidemia, cholesterol, triglycerides, diabetes, cardiovascular disease, cardiovascular disease risk factors risk factors, Gulf Cooperation Council, Saudi Arabia, United Arab Emirates, Kuwait, Bahrain, Oman, and Qatar. In addition, this review used backward citation chasing on three systematic reviews.[27]29] The WHO database was used to pool country fact sheets, which then provided the different reported countries fact sheets. Full studies and fact sheets written in English were only included in this narrative review.

\section{Participants, exposures, and outcomes}

\section{Participants}

Children and adolescents were defined as being $\leq 19$ years old.[30] This review included studies undertaken on ostensibly healthy participants from the six countries of the GCC (Saudi Arabia, United Arab Emirates, Kuwait, Bahrain, Oman, and Qatar). Studies on subpopulations, such as expatriates ( $>50 \%$ of the sample), athletic (i.e., soccer players), or disease groups (i.e., type I diabetes), were excluded. Exposures: Physical activity, sedentary time, sleep time, and cardiorespiratory fitness Studies were included if they reported one or more of the three?movement behaviors (PA, SB, and ST) and/or CRF. Studies reporting PA, SB, and ST were included if they employed either objective (i.e., accelerometer) or subjective (i.e., questionnaire) measurement approaches. CRF studies were included if they used either a validated laboratory (direct and indirect) or field (the $20 \mathrm{~m}$ shuttle run and one?mile run/walk) test.

\section{Outcomes: Physical activity, sedentary behaviors, sleep time, cardiorespiratory fitness, and cardiovascular disease risk factors}

Studies on any of the three?movement behaviors were considered when the outcomes were based on defined cut? points for health. These were defined as: MVPA $\geq 60 \mathrm{~min} 7$ days/week; [16] SB (screen time) $\leq 2$ or $\leq 3 \mathrm{~h} /$ day; [31,32] and ST for 9-11 and 8-10 $\mathrm{h}$ for 6-13 and 14-17 years, respectively.[19] Data presented as the proportion (\%) of participants meeting the recommendation for the three?movement behaviors were included. CRF studies were included if reported mean or $\%$ of $\mathrm{VO}_{2 \max }$ $(\mathrm{mL} / \mathrm{kg} / \mathrm{min})$, predicted $\mathrm{VO}_{2 \max }$, number of laps completed, or performance time in minutes, and separated by sex. Studies measuring traditional CVD risk factors such as dyslipidemia, hypertension, diabetes mellitus, and obesity were included if presented alongside any of the three?movement behaviors and CRF.[33] 


\section{Study designs}

Cross? ?sectional, prospective, and retrospective studies were eligible for this review.

\section{Study selection}

The search strategy, study selection, and data extraction were undertaken by a single author (MA). Stage 1: Searching for articles on the databases with the key terms as mentioned previously in the search method. Stage 2: Titles that included any of the key terms were selected. Stage 3: Abstracts were reviewed to identify the exposure and outcomes. Stage 4: Fullotext screening of selected articles. Stage 5: Only eligible studies were included that met the narrative review inclusion criteria.

\section{Data extraction and categorization}

The following information was extracted from each study: Country, author, sample characteristics (i.e., age, sex), measurement instrument, proportion meeting the recommendation or mean (of the specific variable), and correlations with CVD risk factors.

\section{RESULTS}

\section{Study selection}

One hundred and twenty?three studies were eligible for inclusion in this review [Figure 1]. Eighty?eight studies were excluded, which in four studies expatriate participation were more than $50 \%$ of the sample size,[34目37] two studies were abstract only, $[38,39]$ one study included participants aged up to 23 years old,[40] and one study was specific to athletes.[41] In addition, 79 studies were excluded that did not use internationally recognized cut offs for the movement behaviors,[42] and one study did not separate $\mathrm{VO}_{2 \max }$ by sex.[43] After screening for eligible and duplicated studies and fact sheets, 35 studies were included in this narrative review $(P A=13, S B=13, S T=1$, and $C R F=8)$.

\section{Physical activity}

\section{Subjective measurements}

Ten studies met the inclusion criteria of measuring MVPA for 7 days/week [Table 1]. Five studies used the Arab Teens Lifestyle Study (ATLS) questionnaire on both sexes with an age range from 13 to 19 years old. Daily MVPA for males ranged between $29 \%$ and $70 \%$ and for females $4 \%-$ $39 \% .[44,45,48,53,56]$ Five studies used the Global School 0 based Student Health Survey (GSHS) questionnaire on both sexes aged $13-17$ years old, which $16 \%-32 \%$ and $8 \%-14 \%$ of males and females, respectively, met the guidelines.[49,50,52,54,55]

\begin{tabular}{|c|c|}
\hline $\begin{array}{c}\text { Records screened } \\
(\mathrm{n}=123)\end{array}$ & \multicolumn{1}{c}{$\begin{array}{c}\text { Records excluded } \\
(\mathrm{n}=8)\end{array}$} \\
$4=50 \%$ were expatriate \\
$2=$ only abstract \\
$1=$ Athletes \\
$1=$ Age ranged $14-23$ years
\end{tabular}




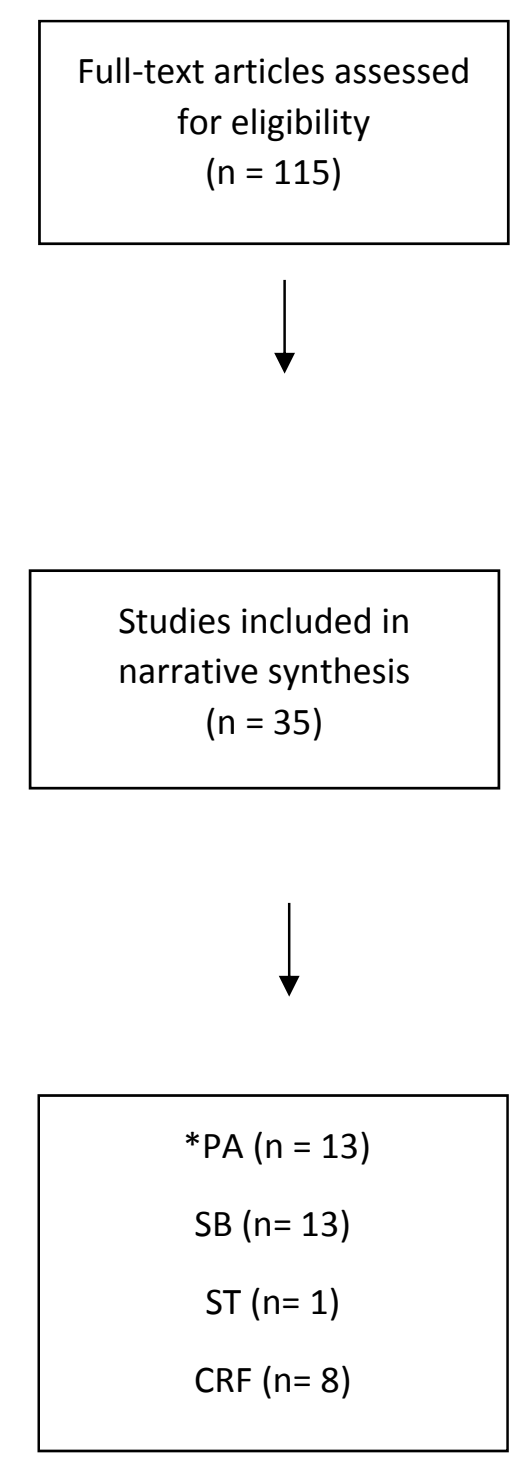

$\longrightarrow \quad$\begin{tabular}{l}
\multicolumn{1}{l}{$\begin{array}{l}\text { Full-text articles excluded, with } \\
\text { reasons } \\
(n=79)\end{array}$} \\
$\begin{array}{l}\text { Studies did not use the } \\
\text { recommended guidelines for each } \\
\text { behaviour* }\end{array} \quad(n=1)$ \\
Combined the results of $\mathrm{VO}_{2 \max }$ for \\
both sex
\end{tabular}

$$
(n=35)
$$

$$
\begin{aligned}
& \text { *PA }(n=13) \\
& \text { SB }(n=13) \\
& \text { ST }(n=1) \\
& \text { CRF }(n=8)
\end{aligned}
$$

\author{
*PA $\geq 60$ minutes/ day \\ $\mathrm{SB} \leq \mathbf{2}$ or $\leq 3 \mathrm{~h} / \mathrm{day}$ \\ $\mathrm{ST} \geq 9$ to $11 \mathrm{~h} /$ day (6-13 years) \\ 8 to $10 \mathrm{~h} /$ day (14-17 years)
}

Figure 1. Flow diagram of selected and extracted articles. 
Table 1: Physical activity prevalence and correlations with health outcomes

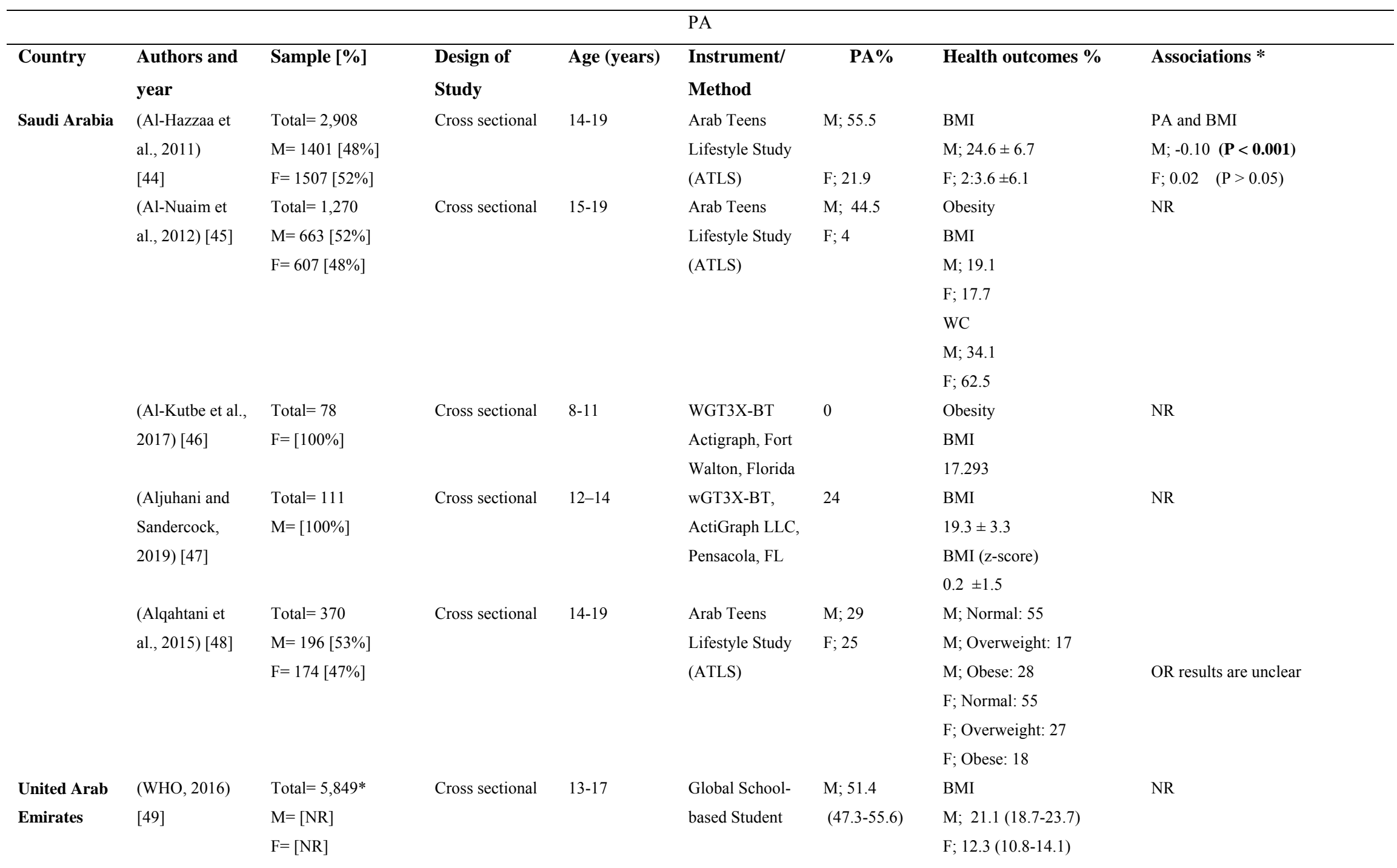




\begin{tabular}{|c|c|c|c|c|c|c|c|c|}
\hline & & & & & $\begin{array}{l}\text { Health Survey } \\
\text { (GSHS) }\end{array}$ & $\begin{array}{l}F ; 67.6 \\
(64.4-70.7)\end{array}$ & & \\
\hline \multirow[t]{5}{*}{ Bahrain } & (WHO, 2016) & Total $=7,141^{*}$ & Cross sectional & $13-17$ & Global School- & M; 26.0 & Obesity & NR \\
\hline & {$[50]$} & $\mathrm{M}=[\mathrm{NR}]$ & & & based Student & $(24.1-27.9)$ & M; $18.6(16.5-20.9)$ & \\
\hline & & $\mathrm{F}=[\mathrm{NR}]$ & & & Health Survey & & & \\
\hline & & & & & (GSHS) & F; 12.6 & F; 17.1 (15.9-18.4) & \\
\hline & & & & & & $(11.2-14.1)$ & & \\
\hline \multirow[t]{15}{*}{ Kuwait } & (Hashem et al., & Total $=351$ & Cross sectional & $14.6-17.6$ & Actigraph & M; 5.6 & NR & NR \\
\hline & 2018) [51] & $\mathrm{M}=162[46 \%]$ & & & GT1M activity & & & \\
\hline & & $\mathrm{F}=189[54 \%]$ & & & monitor & $\mathrm{F} ; 1.6$ & & \\
\hline & & & & & (Actigraph, & & & \\
\hline & & & & & LLC, Pensacola, & & & \\
\hline & & & & & FL, USA) & & & \\
\hline & (WHO, 2015) & Total $=3,637^{*}$ & Cross sectional & $13-17$ & Global School- & $\mathrm{M} ; 18.1$ & Obesity & NR \\
\hline & {$[52]$} & $\mathrm{M}=[\mathrm{NR}]$ & & & based Student & $(15.2-21.3)$ & M; 21.1 (18.7-23.7) & \\
\hline & & $\mathrm{F}=[\mathrm{NR}]$ & & & Health Survey & & & \\
\hline & & & & & (GSHS) & F; 13.1 & F; $12.3(10.8-14.1)$ & \\
\hline & & & & & & $(11.0-15.4)$ & & \\
\hline & (Allafi et al., & Total $=906$ & Cross sectional & $14-19$ & Arab Teens & $\mathrm{M} ; 70.5 \%$ & Obesity & NR \\
\hline & 2014) [53] & $\mathrm{M}=463[51 \%]$ & & & Lifestyle Study & & $\mathrm{M} ; 25.5 \%$ & \\
\hline & & $\mathrm{F}=443[49 \%]$ & & & (ATLS) & $\mathrm{F} ; 39.2 \%$ & & \\
\hline & & & & & & & $\mathrm{F} ; 21.3 \%$ & \\
\hline \multirow[t]{4}{*}{ Oman } & (WHO, 2005) & Total $=2,979^{*}$ & Cross sectional & $13-15$ & Global School- & $\mathrm{M} ; 32.1 \pm 3.6$ & NR & NR \\
\hline & {$[54]$} & $\mathrm{M}=[\mathrm{NR}]$ & & & based Student & & & \\
\hline & & $\mathrm{F}=[\mathrm{NR}]$ & & & Health Survey & $\mathrm{F} ; 13.5 \pm 2.5$ & & \\
\hline & & & & & (GSHS) & & & \\
\hline
\end{tabular}




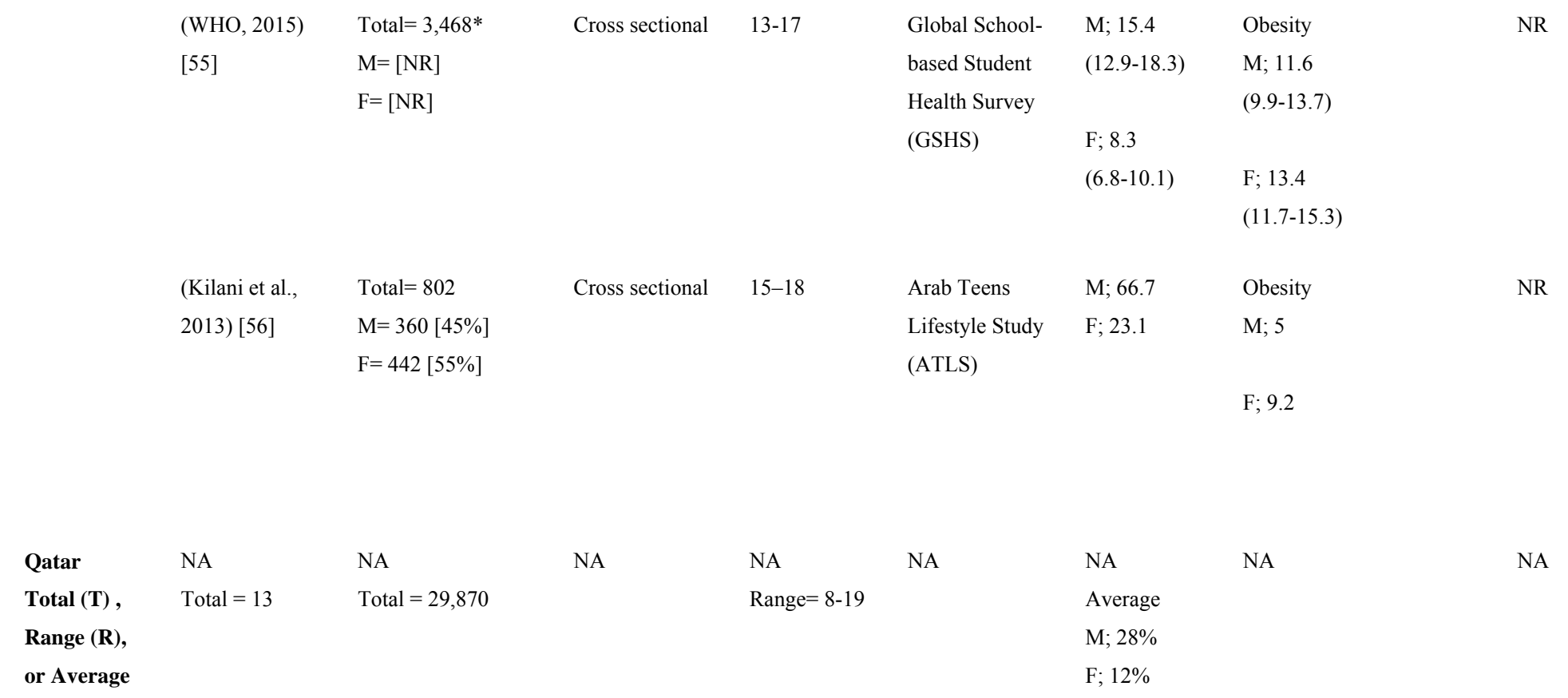

*Associations represented as OR, *Sample was not separated by sex. P=P value, NR=Not reported, NA=Not available, GSHS=Global School based Student Health Survey, ATLS=Arab Teens Lifestyle Study, OR=Odds ratio, PA=Physical activity, BMI: Body mass index 


\section{Objective measurements}

Three studies used an objective measure of PA [Table 1]. Two studies used the ActiGraph

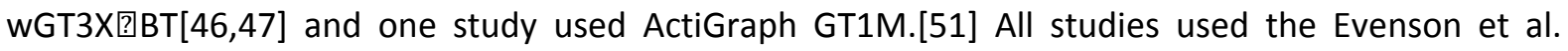
cut? point for MVPA, which was validated on children from the United States of America aged 5-8 years old.[57] Participants aged from 8 to 17.6 years old. One study included both sexes,[51] one study included only females,[46] and one study included only males.[47] These studies revealed that the proportion meeting the PA guideline ranged from $7 \%$ to $24 \%$ for males, and from $0 \%$ to $2 \%$ for females.[46,47,51]

\section{Relationship with cardiovascular disease risk factors}

One study using the ATLS questionnaire[44] investigated the relationship between PA and body mass index (BMI) $(\mathrm{kg} \cdot \mathrm{m} 2)$ and reported a negative association in males but this was positive in females [Table 1].

\section{Sedentary behavior}

\section{Subjective measurements}

Thirteen studies investigated SB by questionnaire. Participants were aged between 13 and 19 years old across both sexes [Table 2]. Four studies[44,48,53,56] used the ATLS questionnaire (cut? point for screen time of $\leq 2 \mathrm{~h} / \mathrm{d}$ ), [62] with $4 \%-55 \%$ and $3 \%-45 \%$ of males and females respectively, meeting the guideline. The GSHS questionnaire (cut?point for screen time $\leq 3 \mathrm{~h} / \mathrm{d}$ ) was used in 9 studies, with

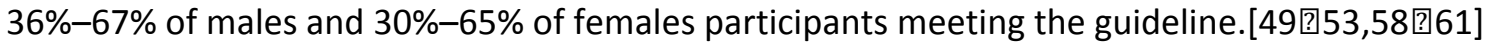

\section{Objective measurements}

No studies were identified that measured sedentary time using an objective method. Relationship with cardiovascular disease risk factors One study investigated SB with BMI ( $\mathrm{kg} \cdot \mathrm{m} 2),[44]$ reporting a non-significant and trivial correlations in male and female participants [Table 2].

\section{Sleep time}

\section{Subjective measurement}

One study used the ATLS questionnaire to determine ST on both sexes aged 15-18 years old.[56] This study found that $23 \%$ of the participants met the ST recommendation of $\geq 8 \mathrm{~h} /$ day [Table 3].

\section{Objective measurement}

No studies were identified that measured ST using an objective method.

\section{Relationship with cardiovascular disease risk factors}

No studies were identified that measured ST and its relationship to CVD risk factors.

\section{Cardiorespiratory fitness}

\section{Field measurements}

Five studies used field tests to estimate CRF in participants aged 9-17 years old [Table 4]. Three studies were male only, $[47,68,69]$ and two included both both sexes.[66,67] Three studies used the $20 \mathrm{~m}$ shuttle run test, but with different protocols (Léger, PACER, The Queen's University of Belfast). These studies found that male and female participants had a mean predicted $\mathrm{VO}_{2 \text { peak }}$ of 43 and $36 \mathrm{~mL} / \mathrm{kg} / \mathrm{min}$, 
respectively.[47,66,67] Two studies used the one? mile walk/ run test (male only) and reported a mean performance time of $10 \mathrm{~min} .[68,69]$

\section{Laboratory measurements}

Three studies used a direct measurement of CRF on male participants aged 7-18 years old during treadmill exercise [Table 4] and reported a mean $\mathrm{VO}_{2 \text { peak }}$ of $41.9 \mathrm{~mL} / \mathrm{kg} / \mathrm{min} .[64,65,70]$

\section{Relationship with cardiovascular disease risk factors}

Three CRF field test studies investigated the relationship between CRF and BMI [Table 4]. Studies that used the $20 \mathrm{~m}$ shuttle run test to estimate $\mathrm{VO}_{2 \text { peak }}$ in male and female participants found weak correlations with BMI $(\mathrm{kg} \cdot \mathrm{m} 2)[66,67]$ [Table 4]. One study that used the one?mile walk/run test and found a positive correlation (only male) between performance time and BMI (kg.m2).[69] Onelaboratory study examined directly measured CRF withseveral CVD risk factors,[71] and found a moderate correlation with BMI $(\mathrm{kg} \cdot \mathrm{m} 2)$ and body fat $\%$, and weak correlations with a range of blood lipid outcomes and blood pressure [Table 4].

\section{DISCUSSION}

This is the first narrative review to synthesize movement behaviors (PA, SB, and ST) and CRF in relation to CVD risk factors in children and adolescents from the GCC. Previous research has highlighted the importance of meeting the cut?points for the movement behaviors and CRF to reduce CVD risk factors[11013,24,72] In addition, meeting all the three?movement behaviors .combined has been found to be associated with more favourable health outcomes.[73] This review indicated that there are only 27 studies on movement behaviors (13 PA, 13 SB, and 1 ST) and eight for CRF on children and adolescents from the GCC. The proportion meeting the movement behavior guidelines were $28 \%(P A)$, $56 \%$ (SB), and 23\% (ST) among GCC children. Participants mean $\mathrm{VO}_{2 \max }$ was 42 and $36 \mathrm{~mL} / \mathrm{kg} / \mathrm{min}$ for males and females, respectively, and the mean one?mile walk/run test (male only) performance was 10 min. This review also revealed that few studies examined PA, SB, and CRF in relation to different CVD risk factors (mainly BMI), which overall found a weak relationship. $[44,48,64,65,67,68,70]$ 
Table 2: Sedentary behaviour (screen time) prevalence and correlations with health outcomes

SB

\begin{tabular}{|c|c|c|c|c|c|c|c|c|}
\hline $\begin{array}{l}\text { Countr } \\
\mathbf{y}\end{array}$ & Authors & Sample [\%] & $\begin{array}{l}\text { Design of } \\
\text { Study }\end{array}$ & Age (y) & Instrument/ Method & SB\% & Health outcomes \% & Associations * \\
\hline Saudi & (Al-Hazzaa & Total $=2,908$ & Cross sectional & $14-19$ & Arab Teens Lifestyle Study (ATLS) & $\mathrm{M} ; 16$ & BMI $\left(\mathrm{kg} / \mathrm{m}^{2}\right)$ & Obesity with SB \\
\hline \multirow[t]{10}{*}{ Arabia } & et al., 2011) & $\mathrm{M}=1401[48 \%]$ & & & & & $\mathrm{M} ; 24.6 \pm 6.7$ & \\
\hline & [44] & $\mathrm{F}=1507[52 \%]$ & & & & $\mathrm{F} ; 9$ & F; $23.6 \pm 6.1$ & $\mathrm{M} ; 0.02(\mathrm{P}>0.05)$ \\
\hline & & & & & & & & $\mathrm{F} ;-0.03(\mathrm{P}>0.05)$ \\
\hline & (Alqahtani & Total $=370$ & Cross sectional & $14-19$ & Arab Teens Lifestyle Study (ATLS) & $\mathrm{M} ; 25$ & M; Normal: 55 & Screen time (hours \\
\hline & et al., 2015) & $\mathrm{M}=196[53 \%]$ & & & & $\mathrm{F} ; 22$ & M; Overweight: 17 & per day) and BMI \\
\hline & [48] & $\mathrm{F}=174[47 \%]$ & & & & & M; Obese: 28 & M; Overweight: OR 2.58 (P 0.02) \\
\hline & & & & & & & F; Normal: 55 & M; Obese: OR $9.63(\mathrm{P}<0.001)$ \\
\hline & & & & & & & F; Overweight: 27 & \\
\hline & & & & & & & F; Obese: 18 & F; Overweight: OR $4.75(\mathrm{P}<0.01)$ \\
\hline & & & & & & & & F; Obese: OR $7.41(\mathrm{P}<0.001)$ \\
\hline United & (WHO, & Total $=2,581^{*}$ & Cross sectional & $13-15$ & Global School-based Student Health & $\mathrm{M} ; 55$ & Obesity & NR \\
\hline Arab & 2010) [58] & $\mathrm{M}=[\mathrm{NR}]$ & & & Survey (GSHS) & & $\mathrm{M} ; 17.1 \pm 1.6$ & \\
\hline \multirow[t]{6}{*}{ Emirates } & & $\mathrm{F}=[\mathrm{NR}]$ & & & & $\mathrm{F} ; 45$ & & \\
\hline & & & & & & & $\mathrm{F} ; 14.2 \pm 1.2$ & \\
\hline & (WHO, & Total $=5,849^{*}$ & Cross sectional & $13-17$ & Global School-based Student Health & M; 49 & Obesity & NR \\
\hline & 2016) [49] & $\mathrm{M}=[\mathrm{NR}]$ & & & Survey (GSHS) & & M; 21.1 (18.7-23.7) & \\
\hline & & $\mathrm{F}=[\mathrm{NR}]$ & & & & $\mathrm{F} ; 32$ & & \\
\hline & & & & & & & $\mathrm{F} ; 12.3(10.8-14.1)$ & \\
\hline
\end{tabular}




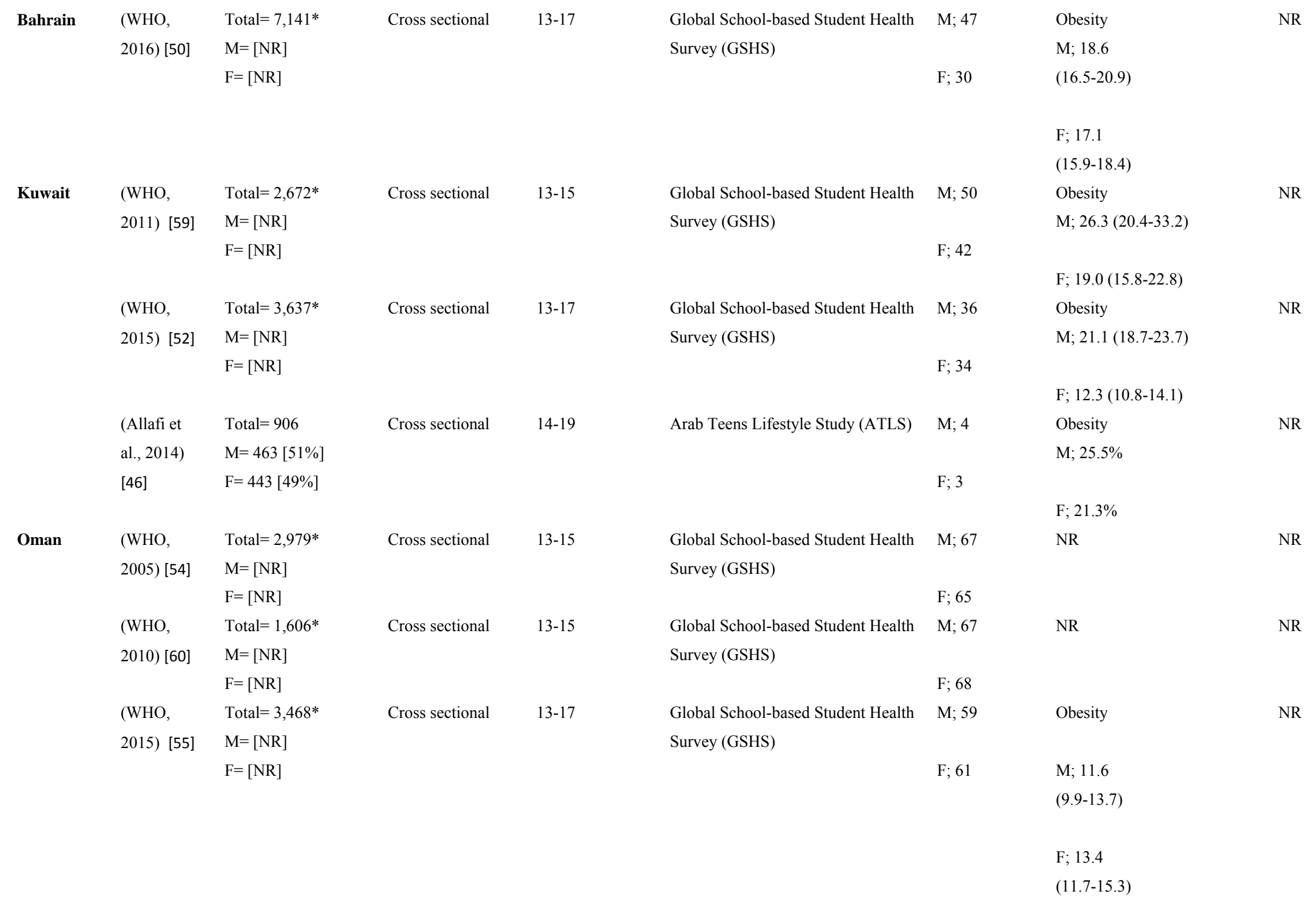



(Kilani et Total $=802$
al., 2013) $\quad \mathrm{M}=360[45 \%]$
[56] $\quad \mathrm{F}=442[55 \%]$

Cross sectional

$15-18$

Arab Teens Lifestyle Study (ATLS)

$\mathrm{M} ; 55$

F; 45

Obesity

M; 5

Qatar

(WHO, Total $=2021 *$

Cross sectional

13-17

Global School-based Student Health

M; 56

F; 9.2

2011) [61] $\mathrm{M}=[\mathrm{NR}]$

$\mathrm{F}=[\mathrm{NR}]$

Survey (GSHS)

M; 25.3

(20.5-30.8)

F; 45

F; 10.8

$(8.0-14.3)$

Total (T), $\quad$ Total $=13 \quad$ Total $=36,940$

Range $=13-19$

Average $=$

$\mathrm{M} ; 45 \%$

F; $39 \%$

or Average

*Associations represented as OR, *Sample was not separated by sex. P=P-value, GSHS=Global School-based Student Health Survey, ATLS=Arab Teens Lifestyle Study, OR=Odds ratio, PA=Physical activity, BMI: Body mass index, NR=Not reported, NA=Not available, $\mathrm{SB}=$ Sedentary behavior

Table 3: Sleep time prevalence and correlations with health outcomes

ST

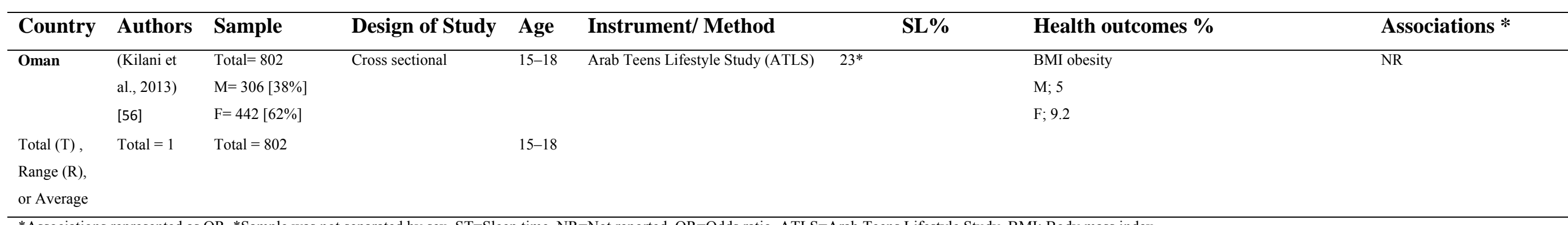

*Associations represented as OR, *Sample was not separated by sex. ST=Sleep time, NR=Not reported, OR=Odds ratio, ATLS=Arab Teens Lifestyle Study, BMI: Body mass index 
Table 4: Cardiorespiratory fitness prevalence and correlations with health outcomes

\section{CRF}

\begin{tabular}{|c|c|c|c|c|c|c|}
\hline Country & Authors & Sample & Age & Instrument/ Method & $\begin{array}{c}\mathrm{VO}_{2 \max }\left(\mathrm{ml}_{.} \mathrm{kg}^{-1} \cdot \mathrm{min}^{-1}\right) \text { or minutes } \\
\text { Mean SD }\end{array}$ & Associations * \\
\hline \multirow[t]{6}{*}{ Saudi Arabia } & (Al-Hazzaa et al., 1994) & Total $=212$ & $7-12$ & Graded Exercise Testing & $\mathrm{M} ; 48.4 \mathrm{SD}[\mathrm{NR}]$ & $\mathrm{VO}_{2 \max }$ and body fat $\%-0.55$ \\
\hline & [63] & $\mathrm{M}=[100 \%]$ & & Ergospirometry on treadmill & & $\begin{array}{l}\text { After controlling for age, BMI and body fat \%: } \\
\mathrm{VO}_{2 \max } \text { and TC }-0.17(\mathrm{P}>0.05) \\
\mathrm{VO}_{2 \max } \text { and } \mathrm{TG}-0.11(\mathrm{P}>0.05) \\
\mathrm{VO}_{2 \max } \text { and } \mathrm{HDL} 0.01(\mathrm{P}>0.05) \\
\mathrm{VO}_{2 \max } \text { and } \mathrm{LDL}-0.12(\mathrm{P}>0.05) \\
\mathrm{VO}_{2 \max } \text { and } \mathrm{HDL} \mathrm{L} / \mathrm{C} 0.11(\mathrm{P}>0.05) \\
\mathrm{VO}_{2 \max } \text { and } \mathrm{SBP}-0.01(\mathrm{P}>0.05) \\
\mathrm{VO} 2 \max \text { and } \mathrm{DBP}-0.08(\mathrm{P}>0.05)\end{array}$ \\
\hline & (Al-Hazzaa, 2001) [64] & Total $=137$ & $7-15$ & Graded Exercise Testing & $\mathrm{M} ; 49.6 \mathrm{SD}[\mathrm{NR}]$ & $\mathrm{VO}_{2 \max }$ and $\mathrm{BMI}-0.59$ \\
\hline & & $\mathrm{M}=[100 \%]$ & & Ergospirometry on treadmill & & $\mathrm{VO}_{2 \max }$ and body fat $\%-0.65$ \\
\hline & (Aljuhani and & Total $=111$ & $12-14$ & 20 meters shuttle run test (PACER) & $\mathrm{M} ; 38.5 \pm 0.5$ & NR \\
\hline & Sandercock, 2019) [47] & $\mathrm{M}=[100 \%]$ & & & & \\
\hline Kuwait & (El-Wahab, 1982) [65] & $\begin{array}{l}\text { Total }=7 \\
\text { M }[100 \%]\end{array}$ & $10-14$ & $\begin{array}{l}\text { Graded Exercise Testing Ergospirometry on } \\
\text { treadmill }\end{array}$ & $\mathrm{M} ; 27.6 \pm 5$ & NR \\
\hline \multirow[t]{7}{*}{ Oman } & (Al Barwani et al., 2001) & Total $=147$ & $15-16$ & 20 meters shuttle run test ( $L^{\prime}$ eger) & $\mathrm{M} ; 44.0 \pm 6.3$ & $\mathrm{VO}_{2 \max }$ and BMI (M) 0.10 \\
\hline & [66] & $\begin{array}{l}\mathrm{M}=64[44 \%] \\
\mathrm{F}=83[56 \%]\end{array}$ & & & $\mathrm{F} ; 36.5 \pm 4.5$ & $\mathrm{VO}_{2 \max }$ and $\mathrm{BMI}(\mathrm{F}) 0.342$ \\
\hline & (Albarwani et al., 2009) & Total $=529$ & $15-16$ & 20 meters shuttle run test (The Queen's & $\mathrm{M} ; 46.25 \pm 8.05$ & $\mathrm{VO}_{2 \max }$ and BMI (M) 0.1705 \\
\hline & {$[67]$} & $\mathrm{M}=245[46 \%]$ & & University of Belfast protocol) & $\mathrm{F} ; 35.8 \pm 8.55$ & $\mathrm{VO}_{2 \max }$ and BMI (F) 0.1945 \\
\hline & & $\mathrm{F}=284[54 \%]$ & & & & \\
\hline & (Al-Shamli, A., 2010) & Total $=330$ & $16-17$ & one mile walk/run & $\mathrm{M} ; 7.56 \pm 1.59$ & NR \\
\hline & [68] & $\mathrm{M}=[100 \%]$ & & & & \\
\hline
\end{tabular}



(Hassan and Al-Kharusy, Total=109

$\mathrm{M}=1215[77 \%]$

Range $=7-17$

$\mathrm{F}=367 \quad[23 \%]$
Average $\mathrm{VO}_{2 \max }(\mathrm{ml} . \mathrm{kg}-1 . \mathrm{min}-1)=$

M; 42

F; 36

Average 1 mile walk/run (minutes)=

M 10

*Associations represented as OR, *Sample was not separated by sex. CRF: Cardiorespiratory fitness, $\mathrm{NR}=$ Not reported, $\mathrm{OR}=\mathrm{Odds}$ ratio, $\mathrm{P}=\mathrm{P} \quad$ value, $\mathrm{SD}=\mathrm{Standard}$ deviation,

$\mathrm{TC}=$ Total cholesterol, $\mathrm{TG}=$ Triglyceride, $\mathrm{SBP}=$ Systolic blood pressure, $\mathrm{DBP}=$ Diastolic blood pressure, $\mathrm{LDL}=$ Low density lipoprotein, HDL=High density lipoprotein, $\mathrm{BMI}=\mathrm{B}$ ody mass

index, $\mathrm{VO}_{2 \max }=$ Maximal oxygen uptake 


\section{Movement behaviors (PA, SB, and ST)}

The literature has emphasized the health benefits associated with meeting different movement behaviors.[11囵13] The proportion meeting the PA guideline in children from the GCC is low, and it indicates that males are more active than females, $28 \%$ and $12 \%$, respectively, which is consistent with the literature across the world.[74] In addition, males (45\%) adhere more to SB guidelines than females (39\%). This might explain why PA prevalence in GCC children is low, especially in females, as SB displaced being physically active.[75] ST data for children from the GCC are limited to a single study, which revealed that only $23 \%$ of both sexes met the ST guideline.[56] Currently, it is recommended to simultaneously meet all the three? movement behaviors for optimal health,[42] which has yet to be investigated among children from the GCC. In a Canadian sample of 1,126 children aged 12-17 years old, only $5.5 \%$ met all the three recommendations, and that meeting none of the three recommendations was associated with $8 / 10$ of unhealthy indicators. [76] In addition, recent evidence on 7,372 children aged 9-11 years old from 12 different countries, found that only $7 \%$ met all the movement behaviour recommendations, and was associated with a lower BMI z[?score.[77] Thus, further research should aim to investigate these movement behaviors jointly in children from GCC, to provide a more comprehensive insight into their current health status. This review revealed that the majority of movement behavior studies (24 out of 27) were based on subjective measurements, which are prone to reporting bias and likely to lead to over or underreporting of movement behaviors.[78080] Of note is that this review identified that the proportion of children meeting the PA guideline was over?reported when comparing the questionnaire (males $41 \%$ and females $23 \%$ ) to the accelerometer (males 15\% and females 1\%). In addition, all studies were cross-sectional, which cannot infer causality with CVD risk factors. Further, no studies have investigated the three?movement behaviors integratedly in association with CVD risk factors, and only few studies (2 out of 27) have explored single?movement behaviors in relation to BMI,[44] which is a questionable measure of adiposity in children.[81] Thus, the association between PA, SB, and ST and CVD risk factors in children from the GCC is currently poorly understood.

\section{Cardiorespiratory fitness}

Although debate exists on CRF and its association with CVD risk factors due to the confounding impact of body size and adiposity,[82[84] it has been found that CRF tests can evaluate the function of cardiovascular system and predict CVD risk factors in children and adolescents. $[21,85] \mathrm{A}$ recent systematic review provided international CRF cut off points to help identify children and adolescents with elevated CVD risk.[24]This systematic review illustrated that the minimum average CRF level for males and females 8-17 years old is 42 and $35 \mathrm{~mL} / \mathrm{kg} / \mathrm{min}$, respectively. [24] Data from the GCC studies indicate that the mean CRF for male and female participants was $42.4 \pm 5.0$, and $36.2 \pm 6.5 \mathrm{~mL} / \mathrm{kg} / \mathrm{min}$, respectively, which are slightly above the recommended cut off points. However, there is no information on the proportion of children from the GCC meeting the CRF cut? point and this needs to be addressed in future research.

In children from the GCC, there are few studies investigating the association between CRF and CVD risk factors. Only one study ( 1 out of 8 ) examined CRF in relation to multiple CVD risk factors and reported weak associations. [63] In addition, four studies examined the association of CRF with obesity which found weak correlations.[64,66,67,69] All CRF studies were a cross-sectional design, which cannot draw a conclusion about the direction of the causal relationship between CRF and CVD risks factors. Unfortunately, this narrative review found that the majority of CRF data were reported in male participants meaning potential sex differences are currently unknown.

\section{Strengths and limitations of this review}


The main strength of this review was including studies that are based on the recommended cut?off for each movement behavior. In addition, this review only considered studies that used valid instruments or tests and recognized questionnaires. As with all studies, some limitations must be acknowledged. This review was limited to three databases, which might miss other studies in other databases engines. In addition, the search only included studies in English language, thereby excluding data in the Arabic language.

\section{RECOMMENDATIONS AND SUMMARY}

- Since all the three?movement behaviors are considered as individual risk factors for CVD, and one behavior can potentially replace the other, it is proposed to measure all three behaviors at once for better interpretation of optimal health benefits[42]

-We propose the use of the international recognized recommended cut offs of the three?movement behaviors (PA $\geq 60 \mathrm{~min} /$ day, SB (mostly screen time) $\leq 2 \mathrm{~h} /$ day, and ST for 6-13 years old 9 to $11 \mathrm{~h} / \mathrm{d}$, and $14-18$ years old $8-10 \mathrm{~h} / \mathrm{d}[19,42,86,87]$

- It is recommended to use the Canadian 240Hour Movement Guidelines for Children and Youth, which has cut? off points for each behavior (PA, SB, and ST)[42]

- Future studies should consider using objective methodologies when assessing movement behaviors among GCC children

- When testing the $20 \mathrm{~m}$ shuttle run test, it is important to report the protocol and running speed $(\mathrm{km} / \mathrm{h})$ at the last completed stage[88]

- In CRF studies, broadening the range of participant characteristics of the GCC states should be encouraged

- It is important to establish prospective studies among GCC children, as all the current studies are cross? ?sectional, which cannot infer casualty with CVD risk factors.

Based on cross-sectional studies on GCC countries, few children are meeting the different movement behaviour (PA, SB and ST) guidelines separately, and the mean CRF is only just above the recommended minima. Furthermore, very few studies have investigated these movement behaviors separately and CRF in relation to CVD risk factors in children from GCC. Therefore, future prospective studies in the GCC region on children are needed to understand the health effect on meeting the three? movement behaviors interactively and CRF in relation to CVD risk factors.

\section{Acknowledgment}

The authors would like to extend their sincere appreciation to the Deanship of Scientific Research at King Saud University, Riyadh, Saudi Arabia.

\section{Financial support and sponsorship}

King Saud University.

\section{Conflicts of interest}

There are no conflicts of interest. 


\section{REFERENCES}

1. Secretariat General of the Gulf Cooperation Council. Member States;2019. Available from: http://www.gcc-sg.org/en-us/AboutGCC/MemberStates/pages/Home.aspx. [Last accessed on 2020 May 15].

2. Noncommunicable Diseases Country Profiles. World Health Organization, Switzerland; 2018.

3. Aljefree N, Ahmed F. Association between dietary pattern and risk of cardiovascular disease among adults in the Middle East and North Africa region: A systematic review. Food \& Nutrition Research 2015;59:27486

4. Al Yazeedi B, Berry DC. Childhood overweight and obesity is increasing in Gulf cooperation council countries: A review of the literature. J Transcult Nurs 2019;30:603-15.

5. Al-Daghri NM. Extremely high prevalence of metabolic syndrome manifestations among Arab youth: A call for early intervention. Eur JClin Invest 2010;40:1063-6.

6. Al-Isa A, Akanji AO, Thalib L. Prevalence of the metabolic syndrome among female Kuwaiti adolescents using two different criteria. Br J Nutr 2010;103:77-81.

7. Rizk NM, Yousef M. Association of lipid profile and waist circumference as cardiovascular risk factors for overweight and obesity among school children in Qatar. Diabetes Metab Syndr Obes 2012;5:425.

8. Aziz F, Al Maskari F, Shah SM. Metabolic syndrome among healthy children aged 6 to 12 years in $\mathrm{Al}$ Ain, United Arab Emirates. Pediatrics 2015;135:S4.

9. Pahkala K, Hietalampi H, Laitinen TT, Viikari JS, Rönnemaa T, Niinikoski H, et al. Ideal cardiovascular health in adolescence: Effect of lifestyle intervention and association with vascular intima-media thickness and elasticity (the Special Turku Coronary Risk Factor Intervention Project for Children [STRIP] study). Circulation 2013;127:2088-96.

10. Expert Panel on Integrated Guidelines for Cardiovascular Health and Risk Reduction in Children and Adolescents, National Heart, Lung, and Blood Institute. Expert panel on integrated guidelines for cardiovascular health and risk reduction in children and adolescents: Summary report. Pediatrics 2011;128 Suppl 5:S213-56.

11. Carson V, Hunter S, Kuzik N, Gray CE, Poitras VJ, Chaput JP, et al. Systematic review of sedentary behaviour and health indicators in school-aged children and youth: An update. Appl Physiol Nutr Metab 2016;41:S240-65.

12. Chaput JP, Gray CE, Poitras VJ, Carson V, Gruber R, Olds T, et al. Systematic review of the relationships between sleep duration and health indicators in school-aged children and youth. Appl Physiol Nutr Metab 2016;41:S266-82.

13. Poitras VJ, GrayCE, Borghese MM, Carson V, ChaputJP, Janssen I, et al. Systematic review of the relationships between objectively measured physical activity and health indicators in school-aged children and youth. Appl Physiol Nutr Metab 2016;41:S197-239.

14. van Ekris E, Altenburg TM, Singh AS, Proper KI, Heymans MW, Chinapaw MJ. An evidence-update on the prospective relationship between childhood sedentary behaviour and biomedical health indicators: A systematic review and meta-analysis. Obes Rev 2016;17:833-49. 
15. Chaput JP, Carson V, Gray CE, Tremblay MS. Importance of all movement behaviors in a 24 hour period for overall health. Int J Environ Res Public Health 2014;11:12575-81.

16. Organization, W.H. Global Recommendations on Physical Activity for

Health. World Health Organization, Switzerland; 2010.

17. Robinson TN, Banda JA, Hale L, Lu AS, Fleming-Milici F, Calvert SL, et al. Screen media exposure and obesity in children and adolescents. Pediatrics 2017;140:S97-101.

18. Canabrava KL, Amorim PR, Miranda VP, Priore SE, Franceschini SC. Sedentary behavior and cardiovascular risk in children: A systematic review. Revista Brasileira de Medicina do Esporte 2019;25:433-41.

19. Hirshkowitz M, Whiton K, Albert SM, Alessi C, Bruni O, DonCarlos L, et al. National Sleep Foundation's sleep time duration recommendations: Methodology and results summary. Sleep Health 2015;1:40-3.

20. Cappuccio FP, Taggart FM, Kandala NB, Currie A, Peile E, Stranges S, et al. Meta-analysis of short sleep duration and obesity in children and adults. Sleep 2008;31:619-26.

21. Anderssen SA, CooperAR, Riddoch C, Sardinha LB, Harro M, Brage S, et al. Low cardiorespiratory fitness is a strong predictor for clustering of cardiovascular disease risk factors in children independent of country, age and sex. Eur J Cardiovasc Prev Rehabil 2007;14:526-31.

22. BarkerAR, Gracia-Marco L, Ruiz JR, Castillo MJ, Aparicio-Ugarriza R, González-Gross M, et al. Physical activity, sedentary time, TV viewing, physical fitness and cardiovascular disease risk in adolescents: The HELENA study. Int J Cardiol 2018;254:303-9.

23. Ruiz JR, Ortega FB, Meusel D, Harro M, Oja P, Sjöström M. Cardiorespiratory fitness is associated with features of metabolic risk factors in children. Should cardiorespiratory fitness be assessed in a

European health monitoring system? The European Youth Heart Study. J Public Health 2006;14:94102.

24. Ruiz JR, Cavero-Redondo I, Ortega FB, Welk GJ, Andersen LB, Martinez-Vizcaino V. Cardiorespiratory fitness cut points to avoid cardiovascular disease risk in children and adolescents; what level of fitness should raise a red flag? A systematic review and meta-analysis. Br J Sports Med 2016;50:1451-8.

25. GasparyanAY, Ayvazyan L, Blackmore H, Kitas GD. Writing a narrativebiomedical review: considerations for authors, peer reviewers, and editors. Rheumatol Int 2011;31:1409-17.

26. Zientek LR, Werner JM, Campuzano MV, Nimon K. The use of Google Scholar for research and research dissemination. New Horiz Adult Educ Human Resour Dev 2018;30:39-46.

27. Al-Hazzaa HM. Physical inactivity in Saudi Arabia revisited: A systematic review of inactivity prevalence and perceived barriers to active living. Int J Health Sci (Qassim) 2018;12:50-64.

28. Mabry R, Koohsari MJ, Bull F, Owen N. Asystematic review of physical activity and sedentary behaviour research in the oil-producing countries of the Arabian Peninsula. BMC Public Health 2016;16:1003.

29. Sharara E, Akik C, Ghattas H, Makhlouf Obermeyer C. Physical inactivity, gender and culture in Arab countries: Asystematic assessment of the literature. BMC Public Health 2018;18:639. 
30. World Health Organization. Definition of Key Terms; 2013. Available from:https://www.who.int/hiv/pub/guidelines/arv2013/intro/keyterms/en/\#targetText=Age\%20gro ups\%20and\%20populations\&targetText=|t\%20is\%20recognized\%20that\%20other,10\%20to\%2019\%2 0 years\%20inclusive. [Last accessed on 2019Sep 4].

31. Bar-OnM, BroughtonD, ButtrossS, CorriganS, GedissmanA, De RivasM, et al. Children, adolescents, and television. Pediatrics 2001;107:423-6.

32. World Health Organization, and Centers for Disease Control and Prevention. Global School-Based Student Health Survey (GSHS). Switzerland: World Health Organization; 2013.

33. deGoma EM, KnowlesJW, Angeli F, Budoff MJ, Rader DJ. The evolution and refinement of traditional risk factors for cardiovascular disease. Cardiol Rev 2012;20:118.

34. Asfour LW, Stanley ZD, Weitzman M, Sherman SE. Uncovering risky behaviors of expatriate teenagers in the United Arab Emirates: Asurvey of tobacco use, nutrition and physical activity habits. BMC Public Health 2015;15:944.

35. Wasfi AS, El-Sherbiny AA, Gurashi E, Al Sayegh FU. Sport practice among private secondary-school students in Dubai in 2004. East Mediterr Health J 2008;14:704-14.

36. Matroushi MA. Global School-based Student Health Survey: United Arab Emirates Fact Sheet; 2005. Available from: https://www.who.int/ncds/surveillance/gshs/Oman_fs_2005.pdf. [Last accessed on 2019 Feb15].

37. Alghadir AH, Gabr SA, Iqbal ZA. Television watching, diet and body mass index of school children in Saudi Arabia. Pediatr Int 2016;58:290-4.

38. Farghaly NF, Ghazali BM, Al-Wabel HM, Sadek AA, Abbag Fl. Life style and nutrition and their impact on health of Saudi school students in Abha, Southwestern region of Saudi Arabia. Saudi Med J 2007;28:415-21.

39. Moussa MA, Skaik MB, Selwanes SB, Yaghy OY, Bin-Othman SA. Factors associated with obesity in school children. Int J Obes Relat Metab Disord 1994;18:513-5.

40. Merdad RA, Merdad LA, Nassif RA, El-Derwi D, Wali SO. Sleep habits in adolescents of Saudi Arabia; distinct patterns and extreme sleep schedules. Sleep Med 2014;15:1370-8.

41. Al-Hazzaa HM, Al-Refaee SA, Sulaiman MA, Dafterdar MY, Al-Herbish AS, Chukwuemeka AC. Cardiorespiratory responses of trained boys to treadmill and arm ergometry: Effect of training specificity. Pediatric Exercise Sci 1998;10:264-76.

42. Tremblay MS, Carson V, Chaput JP, Connor Gorber S, Dinh T, Duggan M, et al. Canadian 24-hour movement guidelines for children and youth: An integration of physical activity, sedentary behaviour, and sleep. Appl Physiol Nutr Metab 2016;41:S311-27.

43. Alghadir AH, Gabr SA, Iqbal ZA, Al-Eisa E. Association of physical activity, Vitamin E levels, and total antioxidant capacity with academic performance and executive functions of adolescents. BMC Pediatr 2019;19:156.

44. Al-Hazzaa HM, Abahussain NA, Al-Sobayel HI, Qahwaji DM, Musaiger AO. Physical activity, sedentary behaviors and dietary habits among Saudi adolescents relative to age, gender and region. Int J Behav Nutr Phys Act 2011;8:140. 
45. Al-Nuaim AA, Al-Nakeeb Y, Lyons M, Al-Hazzaa HM, Nevill A, Collins P, et al. The prevalence of physical activity and sedentary behaviours relative to obesity among adolescents from Al-Ahsa, Saudi Arabia: Rural versus Urban Variations. J Nutr Metab 2012;2012:417589.

46. Al-Kutbe R, PayneA, de LooyA, Rees GA. Acomparison of nutritional intake and daily physical activity of girls aged 8-11 years old in Makkah, Saudi Arabia according to weight status. BMC Public Health 2017;17:592.

47. Aljuhani O, Sandercock G. Contribution of physical education to the daily physical activity of schoolchildren in Saudi Arabia. Int J Environ Res Public Health 2019;16:2397.

48. Alqahtani N, Scott J, Ullah S. Physical activity and sedentary behaviors as risk factors of obesity among rural adolescents. J Child Adolesc Behav 2015;3:185.

49. Sajwani N. Global School-based Student Health Survey: United Arab Emirates Fact Sheet; 2016. Available from: https://www.who.int/ncds/ surveillance/gshs/UAE-2016-gshs-fact-sheet.pdf?ua=1 . [Last accessed on 2019 Feb 15].

50. Haji E. Global School-Based Student Health Survey: Bahrain Fact Sheet; 2016. Available from: https://www.who.int/ncds/surveillance/gshs/gshs_fs_bahrain_2016.pdf . [Last accessed on 2019 Jul 18].

51. Hashem R, Rey-López JP, Hamer M, McMunn A, Whincup PH, Owen CG, et al. Physical activity and sedentary behaviors levels of Kuwaiti adolescents: The study of health and activity among adolescents in Kuwait. J Phys Act Health 2018;15:255-62.

52. Buresli YS. Global School-Based Student Health Survey: Kuwait Fact Sheet; 2015. Available from: https://www.who.int/ncds/surveillance/gshs/2015_GSHS_Kuwait_Fact_Sheet.pdf . [Last accessed on 2019 Jul 18].

53. Allafi A, Al-Haifi AR, Al-Fayez MA, Al-Athari BI, Al-Ajmi FA, Al-Hazzaa HM, et al. Physical activity, sedentary behaviours and dietary habits among Kuwaiti adolescents: Gender differences. Public Health Nutr 2014;17:2045-52.

54. Muzahmi SN. Global School-Based Student Health Survey: Oman Fact Sheet; 2005. Available from: https://www.who.int/ncds/surveillance/gshs/Oman_fs_2005.pdf. Available from: [Last accessed on 2019 Jul 18].

55. Al-Lawati NR. Global School-Based Student Health Survey: Oman Fact Sheet; 2015. Available from: https://www.who.int/ncds/surveillance/gshs/2015_Oman_GSHS_Fact_Sheet.pdf. [Last accessed on 2019 Jul 18].

56. Kilani H, Al-Hazzaa H, Waly MI, Musaiger A. Lifestyle habits: Diet, physical activity and sleep duration among Omani adolescents. Sultan Qaboos Univ Med J 2013;13:510-9.

57. Evenson KR, Catellier DJ, Gill K, Ondrak KS, McMurray RG. Calibration of two objective measures of physical activity for children. J Sports Sci 2008;26:1557-65.

58. Matroushi MA. Global School-based Student Health Survey: UnitedArab Emirates Fact Sheet; 2010. Available from: https://www.who.int/ncds/surveillance/gshs/UAE_2010_FS.pdf. [Last accessed on 2019 Jul 31]. 
59. Matroushi MA. Global School-based Student Health Survey: United Arab Emirates Fact Sheet; 2010. Available from: https://www.who.int/ncds/surveillance/gshs/UAE_2010_FS.pdf. [Last accessed on 2019 Jul 31].

60. Almuzahmi SN. Global School-Based Student Health Survey: Oman Fact Sheet; 2010. Available from: https://www.who.int/ncds/surveillance/gshs/Oman_2010_GSHS_FS.pdf. [Last accessed on 2019 Jul 31].

61. Alkhenji AH. Global School-Based Student Health Survey: Qatar Fact Sheet; 2011. Available from: https://www.who.int/ncds/surveillance/gshs/Qatar_GSHS_FS_2011.pdf. [Last accessed on 2019 Jul 31].

62. Al-Hazzaa HM, Musaiger AO, Group AR. Arab Teens Lifestyle Study (ATLS): Objectives, design, methodology and implications.Diabetes Metab Syndr Obes 2011;4:417.

63. Al-Hazzaa H, Sulaiman M, Al-Matar A, Al-Mobaireek K.Cardiorespiratory fitness, physical activity patterns and coronary risk factors in preadolescent boys. Int J Sports Med 1994;15:267-72.

64. Al-Hazzaa HM. Development of maximal cardiorespiratory function in Saudi boys. A cross sectional analysis. Saudi Med J 2001;22:875-81.

65. El-Wahab FA. Cardio-respiratory differences between trained and untrained children. Phys Educ 1982;39:142.

66. Al Barwani S, Al Abri M, Al Hashmi K, Al Shukeiry M, Tahlilkar K, Al Zuheibi T, et al. Assessment of aerobic fitness and its correlates in Omani adolescents using the 20-metre shuttle run test: A pilot study. J Sci Res Med Sci 2001;3:77-80.

67. Albarwani S, Al-Hashmi K, Al-Abri M, Jaju D, Hassan MO. Effects of overweight and leisure-time activities on aerobic fitness in urban and rural adolescents. Metab Syndr Relat Disord 2009;7:369-74.

68. Al-Shamli A. Physical activity and physiological fitness status of $10^{\text {th }}$ grade male students in AlDhahirah Region, Sultanate of Oman. Curr Res J Soc Sci 2010;2:99-109.

69. Hassan MO, Al-Kharusy W. Physical fitness and fatness among Omani schoolboys: A pilot study. J Sci Res Med Sci 2000;2:37-41.

70. Al-Hazzaa HM, Sulaiman MA. Maximal oxygen uptake and daily physical activity in 7- to 12-yearold boys. Pediatr Exerc Sci 1993;5:357-66.

71. Al-Hazzaa H, Sulaiman M, Al-Mobairaik K, Al-Attas O. Prevalence of coronary artery disease risk factors in Saudi children. J Saudi Heart Assoc 1993;5:126-33.

72. Saunders TJ, Gray CE, Poitras VJ, ChaputJP, Janssen I, Katzmarzyk PT, et al. Combinations of physical activity, sedentary behaviour and sleep: Relationships with health indicators in school-aged children and youth. Appl Physiol Nutr Metab 2016;41:S283-93.

73. Carson V, Chaput JP, Janssen I, Tremblay MS. Health associations with meeting new 24-hour movement guidelines for Canadian children and youth. Prev Med 2017;95:7-13.

74. Guthold R, Stevens GA, Riley LM, Bull FC. Global trends in insufficient physical activity among adolescents: A pooled analysis of 298 population-based surveys with 1.6 million participants. Lancet Child Adolesc Health 2020;4:23-35. 
75. Viner R, Davie M, Firth A. The Health Impacts of Screen Time: A Guide for Clinicians and Parents. Royal College of Paediatrics and Child Health; 2019. Available from: https://www.rcpch.ac.uk/sites/default/files/2018-12/rcpch_screen_time_guide_-_final.pdf . [Last accessed on 2019 Aug 30].

76. Roberts KC, Yao X, Carson V, Chaput JP, Janssen I, Tremblay MS. Meeting the Canadian 24-hour movement guidelines for children and youth. Health Rep 2017;28:3-7.

77. Roman-Viñas B, ChaputJP, Katzmarzyk PT, Fogelholm M, Lambert EV, Maher C, et al. Proportion of children meeting recommendations for 24-hour movement guidelines and associations with adiposity in a 12-country study. Int J Behav Nutr Phys Act 2016;13:123.

78. Sallis JF, Saelens BE. Assessment of physical activity by selfreport: status, limitations, and future directions. Res Q Exerc Sport 2000;71:S1-14.

79. Lauderdale DS, Knutson KL, Yan LL, Liu K, Rathouz PJ. Self-reported and measured sleep duration: How similar are they? Epidemiology 2008;19:838-45.

80. Kang M, Rowe DA. Issues and challenges in sedentary behaviour measurement. Meas Phys Educ Exerc Sci 2015;19:105-15.

81. Telford RD, Telford RM, Welvaert M. BMI is a misleading proxy for adiposity in longitudinal studies with adolescent males: The Australian LOOK study. J Sci Med Sport 2019;22:307-10.

82. Armstrong N, Welsman J. Fact and fiction in youth cardiorespiratory fitness. Int J Phys Educ Fit Sport 2019;8:8-13.

83. Farr C, Middlebrooke AR, Armstrong N, Barker AR, Fulford J, Mawson DM, et al. Objectively measured aerobic fitness is not related to vascular health outcomes and cardiovascular disease risk in 9-10 year old children. J Sports Sci Med 2019;18:513-22.

84. Bailey DP, Savory LA, Denton SJ, Kerr CJ. The association between cardiorespiratory fitness and cardiometabolic risk in children is mediated by abdominal adiposity: The HAPPY study. J Phys Act Health 2015;12:1148-52.

85. Taylor HL, Buskirk E, Henschel A. Maximal oxygen intake as an objective measure of cardiorespiratory performance. J Appl Physiol 1955;8:73-80.

86. World Health Organization. Global Action Plan on Physical Activity 2018-2030: More Active People for a Healthier World. World Health Organization, Switzerland; 2018.

87. Paruthi S, Brooks L, D'Ambrosio C, Hall WA, Kotagal S, Lloyd RM, et al. Recommended amount of sleep for pediatric populations: A consensus statement of the American Academy of Sleep Medicine. J Clin Sleep Med 2016;12:785-6.

88. Tomkinson GR, Lang JJ, Tremblay MS, Dale M, LeBlanc AG, Belanger K, et al. International normative $20 \mathrm{~m}$ shuttle run values from 1142026 children and youth representing 50 countries. Br J Sports Med2017;51:1545-54. 